\title{
Early Readers and Academic Success
}

\author{
Marie A. Leahy ${ }^{1} \&$ Nicole M. Fitzpatrick ${ }^{1}$ \\ ${ }^{1}$ Education Department, Chestnut Hill College, Philadelphia, Pennsylvania, USA \\ Correspondence: Marie A. Leahy, Education Department, Chestnut Hill College, Philadelphia, Pennsylvania, \\ 19118, USA. Tel: 1-215-242-7757. E-mail: leahym@chc.edu
}

Received: July 19, 2017

Accepted: July 28, 2017

Online Published: August 22, 2017

doi:10.5539/jedp.v7n2p87

URL: http://doi.org/10.5539/jedp.v7n2p87

\begin{abstract}
This study examined the degree to which the age that a child learns to read affects his or her future academic success. In recent years, society and school districts, as well as an increasing number of parents, have been urging children to read at earlier ages. Therefore, in order to investigate the research question, an extensive survey was developed and electronically dispersed to individuals eighteen years of age or older. The survey was completed by 220 respondents, collected, and evaluated. The survey results provided quantitative data on respondents' demographic backgrounds as well as their childhood reading and academic histories. A significant number of respondents, $85 \%$, said they regarded the age a child learns to read as important. Over $82 \%$ of early readers, ages three and four, described their overall academic success as either "Excellent" or "Very Good", which was $12 \%$ higher than the respondents who did not learn to read until age six or older. The factors that were not impacted by the age the respondents learned to read was whether or not they went to college or earned advanced degrees. Therefore, while academic success is often perceived as getting good grades in school, is that really enough? The respondents who learned to read at an early age generally earned good grades in school, but that did not necessarily translate to being more likely to go to college or earn an advanced degree, which is a strong measure of overall academic success.
\end{abstract}

Keywords: reading, early education, academic success, college and career ready, Common Core Standards

\section{Introduction}

Societal expectations, countless conflicting research findings, and competitive spirits have been some of the factors that have contributed to parents drawing significant attention and importance to the age at which their children learn to read. While some parents have tried to teach their children to read prior to formal schooling, others have allowed their children to learn at their own pace or at the age that most children are taught to read, in early elementary school. But a common goal that most parents share is that they want their children to be the best, brightest, and most successful students possible. According to Guernsey (2011), television advertisements for baby flashcards, an increase in the accessibility of the internet, countless parenting books, and the growing presence and weight of standardized tests have been some of the more recent causes for the increased pressures that parents and schools have put on children to learn to read. Since reading is one of the most important and valuable skills that every child needs to acquire and consistently improve, there is much controversy and differing opinions about how beneficial and effective early reading is to a student's eventual reading comprehension skills and overall future academic success (Kern \& Friedman, 2014).

Although some research studies promote teaching children to read as early as possible, others have found that there are a variety of factors and variables that influence not only a child's future academic success, but also their readiness to learn to read. According to Kern and Friedman (2008), such factors have been socio-emotional maturity, parent involvement, personality, and gender. Lately, teachers have been put in a compromising position when it comes to this issue since they try to bridge the gap between parent expectations and what is educationally and developmentally appropriate for their students. While most families, educators, and educational standards are aligned to enrich children's minds and to prepare them for their academic futures, there are some philosophical differences that the three segments hold when it comes to children and the best process in which their long-term academic achievement is fostered. 
Assessing the appropriate age to teach children to read and how valuable a factor it is to student academic success has major implications not only for students, but also for teachers, families, school curriculum, standardized tests, and Common Core Standards. Therefore, a literature review on past research studies and relevant articles has been completed and discussed within the body of this research paper. A survey has been developed, distributed, and analyzed to gain insight on the reading experiences and academic successes that people from a broad range of backgrounds have had in order to compare reading age and future academic success with other variables. So, the question that has been researched, examined, and evaluated is: To what degree does the age at which a child learns to read affect his or her academic success?

\section{Literature Review}

\subsection{Introduction}

Numerous studies have found that reading is one of the most valuable fundamental skills that children learn growing up, which aids them in their academic success at future grade levels. With all of the research on the benefits of reading, there has been a debate about the best age to teach children to read, causing two differing philosophical perspectives. The first is that children are never too young to learn how to read. These proponents have cited great amounts of research indicating that children who learn to read prior to their formal schooling benefit more academically than those who learn to read later in childhood or during the primary grades. The other side of the debate focuses on the developmental readiness of children to read, and does not see a great benefit in attempting to teach babies and toddlers to read as early preparation for formal schooling (Caron \& Ponder, 2014). Parents, educators, and children are those who are most affected by this debate since parents want their children to be prepared and to be successful in school, while teachers recognize the developmental concerns and administrative pressures regarding the age at which children learn to read, and what age will prove to be most effective. Children are at the hands of research and what their parents want, which sometimes conflicts with what educators are trained to teach, based on standards, teaching strategies, and developmental considerations.

\subsection{The Importance of Reading}

Learning to read is the skill that a child will use for the rest of his or her life, which will ultimately help and affect their future academic success. Reading has been strongly linked to academic achievement, since reading is incorporated into every subject at higher grade levels (Caron \& Ponder, 2014). Therefore children who are able to read and who have more advanced vocabularies and reading comprehension skills tend not only to do better in school but also to score higher on standardized tests. Children who struggle to learn how to read, or who give up and do not learn at all, have more difficulties with the rest of their education, or unfortunately, are forced to drop out. This happens since the student might be too embarrassed to continue to attend formal schooling (Reading to Young Children, 2012).

Children develop literacy skills and an awareness of language long before they are able to read. These language skills are linked to academic success since language development is fundamental to all areas of learning. Children who lack a strong foundation of language awareness and literacy skills early in life are more likely to fall behind in school leading to less academic success (Reading to Young Children, 2012). Based on prior research from the Institute of Education, children who read for pleasure are likely to do significantly better in school than their peers. Not only is learning to read important, but developing a love for reading is important when it comes to continued academic success (Battye \& Rainsberry, 2013).

There is much debate about whether it is best to teach children to read early at younger ages or even prior to the start of their formal education, or if it is better to teach children to read during first and second grades when they are developmentally prepared. Prior research has shown that children learn the fastest in their first six years of life, which may bolster the philosophy that teaching children to read as early as possible is best (Benefits of Early Reading, 2010). Research has also shown that children must be developmentally and psychologically prepared and ready, otherwise learning to read may be more of a challenge, or even just a superficial skill, which the child does not know how to nurture or advance if uninterested (Kern \& Friedman, 2014). Since reading is one of the most cognitively challenging skills for a child to learn, it is important that children be taught at the proper age so that there is less of a struggle and more ease based on prior language, vocabulary, and sound acquisition.

\subsection{Advantages of Learning to Read Early}

Children who are bright, curious, and developmentally ready to learn how to read are able to start at an early age. Some learn at home prior to the start of their formal education, while others learn in preschool or kindergarten. 
According to Caron and Ponder (2014), parents who answer their children's questions, engage in dialogue, and read to their children, are the ones who set their children up to learn to read at earlier ages. This is because whether parents realize it or not, they are helping to build the foundation that every child needs in order to learn how to read. By putting language and words together, and familiarizing themselves with how books are held, the way words are written, and the sounds that different letters make alone or when joined with vowels or other letters, children begin to make connections and gain confidence with their understanding and abilities.

Early literacy experts argue that children at ages four and five should be exposed to some building blocks of reading. For example, they should learn the letters of the alphabet and their sounds, so that those components of reading are readily "retrievable" from memory when children are asked to start reading words in later grades (Guernsey, 2011). Whether children actually learn to read at age three or age seven, it is just as important for children to have gotten the language, alphabet, and sound exposure, which will aid in their reading development and advancement. Since research has found that children learn the fastest in the first six years of life, many proponents of teaching children to read at earlier ages defend their position by explaining how reading can be picked up faster and can be used throughout their early years to gain more information through the books they read and gain exposure to new vocabulary, moral lessons, and other subject areas (Benefits of Early Reading, 2010).

Growing children's vocabularies has been shown to bolster children's academic success as well as to improve standardized test scores. This is another reason why so many academics as of late have repositioned their views from supporting children's first reading age from six or seven to earlier ages. Another reason why the recommended reading age has dropped recently is because of the decline in literacy rates and the push for lower school entrance ages (Caron \& Ponder, 2014). To help combat the growing decline in literacy, many feel that children who learn to read at younger ages will develop stronger reading foundations and abilities, which will set them up for success in their futures.

\subsection{Advantages of Learning to Read Later in Childhood}

Traditionally, experts have believed that children should learn to read in their first years of schooling, first and second grades. In the past, early childhood education was not as readily available or as common, but lately pre-kindergarten and kindergarten programs have sprouted, which has caused an increase in child enrollment into these classes (Caron \& Ponder, 2014). This growing trend has added not only to the debate about what is the best age to teach children to read, but also what is the best age to begin formal schooling for children? Experts agree that children have individual learning speeds and styles, and mature at their own rate, along with other developmental, social, and biological variables that affect their readiness to begin formal schooling and learning to read. All children have their own interests and personalities, which translate to individual temperaments, all of which affect the age at which a child is ready and able to learn to read (Kern \& Friedman, 2014).

Researchers agree that there is a limit to how young you can go when teaching a child to learn to read, and that it makes no sense to try to teach a baby or toddler how to read, when developmentally speaking, they are just not ready to begin. Although there are parents and educational advocates, like Janet Doman of the Institute for the Achievement of Human Potential, who try to use reading flashcards with babies and toddlers, there are many other parents and educators in the field who believe that children should read when they are ready but should always be exposed to books and be read to by their parents and families. The National Early Literacy Panel published a report in 2009, which was later criticized by some experts due to its narrow view of scientific studies, which de-emphasized the importance of play and conversation in language development, a critical foundation to success in reading. Yet in that report, there was an important synthesis of research on what types of early experiences are most closely related with successful reading, including exposure to letters and an awareness of phonemes in pre-kindergarten and kindergarten (Guernsey, 2011).

There are decades of peer-reviewed research that focuses on the need for a "balanced approach" that is committed to helping children to communicate using spoken and written language, while also helping them to identify individual letters through the alphabet, and to recognize the use of print by holding and observing books (Guernsey, 2011). A more recent study conducted by Kern and Friedman (2014), aimed to gather follow-up data from the Terman Life Cycle Study to explore how age at first reading and age at school entry affect grade school academic achievement, along with some other long term educational and psychological adjustments. This study found that early reading was associated with early academic success, but less "lifelong educational attainment" and worse "midlife adjustment". While Kern and Friedman's research discussed other studies' findings about early reading abilities and how they are directly and indirectly related to long-term reading success, this journal 
article explored how precocious reading ability can dissipate over time, or a child may not be psychosocially prepared or developed enough to enjoy the early reading benefits, and therefore may have a more difficult time adjusting through the academic grade levels. This study's findings support the philosophy that exposing children to books and encouraging good reading behaviors and activities are beneficial, but they will not have all of the positive long-term educational successes if they are not psychosocially developed or ready to read or advance in grade level.

Learning to read later in childhood also allows the student to be helped and taught by a professional educator. These educators have been formally trained and can provide phonics instruction, reading techniques, word recognition activities, and model the reading process to their students. Children who learn to read during their first formal years of education can be monitored by a professional, which allows the teacher to facilitate, scaffold, correct, and even intervene during the reading process when appropriate. Children who learn to read later in their childhood may also benefit by having different types of books at their disposal in the classroom and school library, which a child who learns earlier in their childhood may not have access to. Having an early elementary teacher encourage reading and provide opportunities to read during the school day also encourages positive literacy behaviors and habits, which promotes recreational reading and instills a love and passion for literature (Cullinan, 2000).

\subsection{Variables Affecting Reading and Academic Success}

There are a number of variables that play a role and impact not only the age at which children learn to read, but also their future academic success. There are environmental factors, biological factors, and behavioral factors that can make a major difference in how children learn, and how advanced or behind they might become in later grades. Some of these variables include the following: parental level of education, socioeconomic level, race and culture, family make up and siblings, gender, personality, parental involvement, age at which child begins school, teacher opinions and biases, and technology (Kern \& Friedman, 2014). The highest level of education that a parent has completed does have an impact on children and their academic success. If a parent dropped out of school, then they may not place an important value on education, or may feel insecure about their own knowledge and reading level competencies. This scenario is more likely to have a negative academic effect on a child, since parental encouragement and involvement is so important during the critical years that children learn how to read. On the other hand, if a parent has completed higher education, then they may hold education in higher regard and as a top priority, being more involved with their child's literacy development and academic achievement (Ortiz, Folsom, Otaiba, Greulich, Thomas-Tate, \& Connor, 2012).

The socioeconomic background that a child comes from is another variable that can impact their reading age and future academic success. Children who come from poverty may not receive the proper nourishment to develop physically, emotionally, psychologically, or intellectually in the same way that children from higher social classes frequently do. When a child's basic developmental needs are not met or fostered, then learning to read is typically delayed, and formal schooling will be more of a challenge for that student. Environmental factors that are related to socioeconomic status and affect a child's reading age and academic success include living environment and neighborhood. If a child is living in a dangerous area with violence occurring at all hours of the night, and is sharing a bedroom with five other siblings, then they have some additional concerns than does the child who grows up in a safe middle class suburb, who is put to bed in their own room every night, at a reasonable time, with no outside disturbances (Ortiz et al., 2012). Race and culture can have a significant influence on children's reading age and academic success, since some cultures believe that education is up to schools and teachers, and is not a responsibility of the parent or family. Children whose parents do not assist with homework or educational lessons prior to the start of their formal schooling are at a disadvantage, since that extra reinforcement has been proven to bolster a child's education. Unfortunately, minority children statistically come from lower socioeconomic backgrounds than do Caucasian children, which is part of a larger issue that negatively affects those children and their future academic success (Lesaux, 2012).

Family make up is a variable that is two-fold. In single parent homes a child may not get as much parental attention or guidance as one in a two-parent home receives. A single parent may need to work double shifts to provide for the household, resulting in daycare or limited quality time. A two parent family may be able to afford to have one parent stay home with the child during their early years and upbringing, which likely provides more opportunities for the child to be read to by the parent (Ortiz et al., 2012). Battye and Rainsberry (2013) discussed the findings that having older siblings had a negative effect on children's test scores in three subject areas (math, spelling, and vocabulary) but particularly for vocabulary. Children who have older siblings may not get the same 
opportunities to speak and ask questions as only children or oldest children do, and they may also be spoken for, or may not need to speak to get what they want, need, or want to know. According to Reading to Young Children (2012), if a child does have an older sibling, it is important to encourage the older sibling to read to the child since they will receive individual attention, and will learn to model their older brother or sister.

Other variables such as gender and personality can have an effect on children's academic success and reading age, since males and females develop and mature at different rates. Every child has a different personality and varying preferences in terms of what to do, how to do things, what interests them, and how they learn most effectively (Kern \& Friedman, 2014). A parent's level of involvement with their child, and their education, is also an important factor that contributes to a child's academic success and reading age, since children learn from their parents, and engage in conversation, ask questions, and read together. When parents are involved with their child's education they become aware of educational milestones that are expected, and typically try to facilitate in any way possible at home. The age at which a child enters formal schooling, whether that be pre-kindergarten, kindergarten, or right into first grade will also have a role in a child's academic success. Not only do children benefit from the socialization opportunities that formal schooling offers, but they also have the opportunity to learn about different subjects, engage in read alouds, and explore learning stations in the classroom. Being exposed to books, reading centers, the alphabet, and spoken language earlier in life does help children learn to read when they are ready. Entering a grade when a child is not prepared, or developmentally mature enough, can cause academic struggles, and can make the reading process difficult and unpleasant for the student (Ortiz et al., 2012).

\subsection{Conclusion}

Based on the research and findings discussed, there is still a great deal of work, and studies to be completed, in order to provide answers as to how much of an impact the age at which children learn to read truly relates to their academic success. There will always be a differing of opinion in terms of what parents want for their children, and whether they will urge their children to read as young as possible, or whether it is their philosophy to let their children read and develop at their own pace and with the help of their school teacher. However, there is growing concern that the increase in testing at earlier ages will influence the recommended reading age, pushing the age at which children begin to read lower and lower, which will have negative consequences for our students' future academic success. On the other hand, based on previous research, it is now understood that exposing children to language, the alphabet, books, and new vocabulary as early as possible does benefit children's eventual reading skills. This in turn strengthens their academic success, since reading and reading comprehension carry over into other academic subjects. Being taught to read, or just naturally learning to read at age four or age six, can be equally beneficial in terms of a student's academic success if the proper instruction, materials, books, and developmental timing is respected, encouraged, and available. The goal is for children to develop a love and passion for reading, while improving and exercising the skill at every grade level.

\section{Methods}

A survey of nine demographic questions and twenty questions on reading and academic history was designed based on previous research and the literature review. In the summer of 2016, the survey questions were submitted to the Institutional Review Board at Chestnut Hill College and granted approval. Each survey question had a specific purpose, either to provide specific demographic information on the respondent or to help explain the respondents' reading habits and academic history. Ultimately, the goal of the survey was to compare demographic backgrounds, the age the respondent learned to read, and general academic experience, while examining the degree to which the age a child learned to read affected his or her academic success, taking all research variables into consideration. The demographic questions that were asked were a way of developing a history for each respondent. Since there are many variables that can have a role and impact a person's academic success, it was important to understand each respondent's background and how his or her experiences compared to others. Nomination sampling was utilized during the fall of 2016. Four surveys were initially sent electronically. The first four respondents forwarded the survey and then the pattern continued. All participants were at least eighteen years of age and lived in the United States. The format of the survey was intended to be appealing and user friendly in hopes of garnering a large return. Two hundred twenty-three responses were collected and three responses were removed because more than half of the questions were not answered. The quantitative data obtained from the remaining 220 surveys was analyzed using Excel. 


\section{Results and Discussion}

Of the 220 responses, $76 \%$ were female and $24 \%$ were male with the age breakdown being as follows.

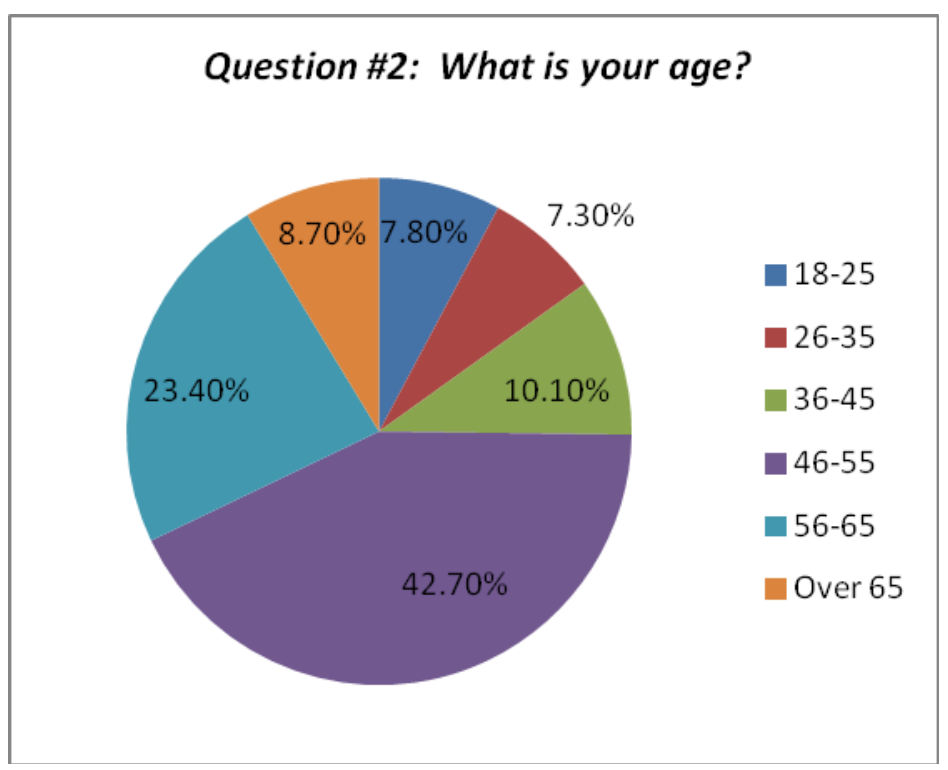

Figure 1. Question \#2 on Survey: What is your age?

The age at which each respondent learned to read was varied. Two respondents did not answer question \#11 (To the best of your knowledge, at what age did you learn to read?). Based on this data, the age the respondents learned to read was not significantly affected by socio-economic status, the level of education of either parent, the year they were born, or whether they came from a single-parent or two-parent home. The extent to which race was a factor could not be determined from this data set because $91.8 \%$ of the respondents were white/Caucasian.

Table 1. Age child learned to read

\begin{tabular}{ccc}
\hline Age & \# of respondents & $\begin{array}{c}\text { \% of 218 } \\
\text { (Two respondents left question blank.) }\end{array}$ \\
\hline 3 & 19 & 8.71 \\
4 & 43 & 19.72 \\
5 & 66 & 30.27 \\
6 & 73 & 33.48 \\
7 & 15 & 6.88 \\
8 & 1 & 0.45 \\
10 or over & 1 & 0.45 \\
\hline
\end{tabular}

As indicated in the research, males tend to mature later than females and thus often learn to read later than females. Since about three-fourths of the number of respondents were female compared to about one-fourth being male, the age at which respondents of each sex learned to read cannot be compared in this study. It is interesting that the two respondents who learned to read at age eight and ten or over were both male.

In answer to question \#26 (Do you think the age you learned to read is important?), 67\% of the respondents replied, "Yes, definitely," 18\% replied, "Somewhat important," and 15\% replied, "No, not really." Clearly, a 
significant number of respondents, $85 \%$, regarded the age they learned to read as either extremely important or somewhat important.

The respondents who self-reported that they viewed their overall academic success as either "Excellent" or "Very Good" was as follows:

Table 2. Respondents who viewed their overall academic success as either "Excellent" or "Very Good"

\begin{tabular}{lcc}
\hline Respondents who learned to read at age 3 or 4 & $51 / 62$ & $82.25 \%$ \\
Respondents who learned to read at age 6 or older & $63 / 90$ & $70 \%$ \\
Respondents who learned to read at age 7 or older & $9 / 17$ & $52.94 \%$ \\
\hline
\end{tabular}

The respondents who learned to read at an early age, three or four years old, and described their overall academic success as either "Excellent" or "Very Good" was $82.25 \%$, which was significantly higher than the respondents who learned to read at age six or older who described their overall academic success as either "Excellent" or "Very Good". Based on the self-determination of the participants in this study, the age at which a child learns to read significantly affects his or her overall academic achievement.

However, getting good grades in school can be very subjective, and what one person values as "good" may be considered "excellent" by someone else. In addition, getting good grades is not the sole determinant of academic success. In addition to grades on a report card, successfully going on to higher education is another determinant of overall academic achievement. The percentage of respondents who learned to read at the age of three and went on to attend at least "some college" was 94.73 , which is noteworthy. Surprisingly, the percentage of respondents who learned to read at the age of four and went on to attend at least "some college" was significantly lower at 83.72 , which was almost identical to the percentage of respondents who learned to read at the age of six, which was $83.56 \%$. Interestingly, the percentage of respondents who learned to read at the age of five and went on to attend "some college" was 92.42 , only slightly lower than those who learned to read at the age of three.

Table 3. Respondents who attended at least "some college"

\begin{tabular}{lll}
\hline Respondents who learned to read at age 3 & $18 / 19$ & $94.73 \%$ \\
Respondents who learned to read at age 4 & $36 / 43$ & $83.72 \%$ \\
Respondents who learned to read at age 5 & $61 / 66$ & $92.42 \%$ \\
Respondents who learned to read at age 6 & $61 / 73$ & $83.56 \%$ \\
\hline
\end{tabular}

As the respondents progressed through their academic careers, the age they learned to read did not seem to predict the level of education they obtained. The respondents who learned to read at the age of seven or older and who earned a Master's Degree was 35.29\% compared with those who learned to read and the age of three or four at $29 \%$.

Table 4. Respondents who obtained a master's degree

\begin{tabular}{lcc}
\hline Respondents who learned to read at age 3 or 4 & $18 / 62$ & $29 \%$ \\
Respondents who learned to read at age 6 or older & $29 / 90$ & $32.22 \%$ \\
Respondents who learned to read at age 7 or older & $6 / 17$ & $35.29 \%$ \\
\hline
\end{tabular}

The respondents who earned a doctoral degree learned to read at ages four, five, and six with a range of $4.54 \%-6.97 \%$. Even though $6.9 \%$ of those who learned to read at age four earned a doctorate compared with $4.54 \%$ of those aged 5 and $5.48 \%$ of those ages six, the differences are insignificant. The one fact that may be worth mentioning is that although $35.29 \%$ of respondents who learned to read at age seven or older earned a master's degree, none of the respondents who learned to read and age seven or higher earned a doctoral degree. 
Table 5. Respondents who obtained a doctoral degree

\begin{tabular}{lll}
\hline Respondents who learned to read at age 4 & $3 / 43$ & $6.97 \%$ \\
Respondents who learned to read at age 5 & $3 / 66$ & $4.54 \%$ \\
Respondents who learned to read at age 6 & $4 / 73$ & $5.48 \%$ \\
\hline
\end{tabular}

\section{Conclusion and Recommendations}

A child who learned to read at the age of three or four is considered an early reader. The majority of people, as well as the majority of respondents in this study, learned to read in kindergarten and first grade at the age of five or six. Over the past two decades there has been a growing trend to get children reading before they enter kindergarten. With the Common Core Standards children in kindergarten are expected to read and be assessed on large amounts of texts, often causing frustration on the part of the children, teachers, and parents. As a result, a new trend is emerging where parents are delaying the start of kindergarten for their children and waiting until they are six years old to enroll them rather than at the typical age of five so their children will not be "behind" and will do well on their tests. History has shown that the vast majority of children will learn to read by the end of first grade because that is the natural time in their growth and development where reading typically takes effect. Pushing children to read before they are ready is truly an injustice. As a result, an inordinate amount of young children now need extra support in the forms of tutoring, additional help from classroom aides, extra small group work, extra homework, and summer school. If so many children need so much extra support to learn to read, they are not being taught at the proper level. Learning to read does not need to be such a chore. It will happen because that is the natural progression once reading readiness skills have been acquired. There will always be some children who will naturally begin reading at an early age, but the vast majority of children learn to read at age five or six.

Although random sampling was not utilized in this study and the results cannot be generalized, the findings shed light on the ongoing conversation of the importance of reading at an early age and the impact on overall academic success. Clearly, learning to read at an early age can give children a boost of confidence and help foster a positive attitude toward school, but it is not the sole determinant of whether or not children will have overall academic success. Often times the understanding of academic success is getting high test scores and good grades, but that should not be the litmus test. Overall academic success should take into consideration whether or not a person was able to go onto higher education and become a productive member of society. The amount of pressure to begin reading at an early age that is put on children today by parents, teachers, schools, and school districts seems unnecessary. In this age of high stakes testing, children begin being tested on their reading skills and comprehension as soon as they are first registered for kindergarten. If the goal of the Common Core Standards is to get children "college and career ready", the age at which they learn to read is not a critical factor.

\section{References}

Battye, C., \& Rainsberry, M. (2013, September 11). Reading for pleasure puts children ahead in the classroom, study finds. Retrieved from http://www.ioe.ac.uk/89938.html

Benefits of Early Reading. (2010, January 1). Retrieved September 7, 2014, from http://www.teachreadingearly.com/benefits-of-early-reading.php

Caron, C., \& Ponder, C. (2014). What's the Best Age to Teach Your Child to Read? Retrieved September 17, 2014, from http://www.learn-to-read-prince-george.com/best-age-read.html

Cullinan, B. (2000). Independent reading and school achievement. School Library Media Research, 3(1523-4320), $1-24$.

Retrieved

from http://www.ala.org/aasl/sites/ala.org.aasl/files/content/aaslpubsandjournals/slr/vol3/SLMR_IndependentRea ding_V3.pdf

Guernsey, L. (2011, May 12). Learning to Read: How Young is Too Young? Retrieved September 17, 2014, from http://www.huffingtonpost.com/lisa-guernsey/learning-to-read-how-youn_b_860964.html

Kern, M., \& Friedman, H. (2014). Early educational milestones as predictors of lifelong academic achievement, midlife adjustment, and longevity. Journal of Applied Developmental Psychology, 419-430. Retrieved from http://www.ncbi.nlm.nih.gov/pmc/articles/PMC2713445/ 
Lesaux, N. (2012). Reading and reading instruction for children from low-income and non-english-speaking households. The Future of Children, 22, 73-88. https://doi.org/10.1353/foc.2012.0010

Ortiz, M., Folsom, J., Otaiba, S., Greulich, L., Thomas-Tate, S., \& Connor, C. (2012). The componential model of reading: Predicting first grade reading performance of culturally diverse students from ecological, psychological, and cognitive factors assessed at kindergarten entry. Journal of Learning Disabilities, 406-417. https://doi.org/10.1177/0022219411431242

Reading to Young Children. (2012, January 1). Retrieved September 7, 2014, from $\mathrm{http}: / /$ www.childtrends.org/?indicators=reading-to-young-children

\section{Copyrights}

Copyright for this article is retained by the author(s), with first publication rights granted to the journal.

This is an open-access article distributed under the terms and conditions of the Creative Commons Attribution license (http://creativecommons.org/licenses/by/4.0/). 